\title{
Propolis gel versus benzydamine in preventing oral mucositis for patients irradiated in head and neck: a preliminary study
}

\author{
Noronha VRAS ${ }^{1}$, Abdo EN ${ }^{1}$, Persio FPCL ${ }^{2}$ and Santos VR ${ }^{1 *}$ \\ ${ }^{1}$ Department of Oral Pathology and Surgery, School of Dentistry, Federal University of Minas Gerais, Belo Horizonte, Brazil \\ ${ }^{2}$ Private Practice, Brazil
}

\begin{abstract}
Oral Mucositis refers to oral mucosa erythematous and ulcerative lesions and is caused by radiation dispensed in the treatment of malignant tumors of the head and neck. Propolis shows several biological activities such as antimicrobial and anti-inflammatory properties. These biological activities should prevent a mucositis. The aim is to verify the effectiveness of Brazilian green propolis in a mucoadhesive gel, alcohol free, in preventing oral mucositis in patients that underwent radiotherapy. This research is characterized as a preliminary study with a mean duration of 12 weeks of patients' follow-up in two groups. The selection of participant's groups was randomized. The 26 selected patients were distributed between two groups, 13 in the benzydamine group and 13 in the propolis group. Patients were assessed on an average of 4.5 times totaling 116 diagnoses of mucositis. The percentage of patients who had mucositis greater or equal to 2 in this study was $30.6 \%$ for the benzydamine group and $29.6 \%$ for propolis gel. For these patients, the propolis gel shows a better performance in maintaining lower rates/grades and recovery of patients from the $17^{\text {th }}$ session of radiotherapy. This work shows a great possibility of further study in Phase III due to its good results and acceptance with patients.
\end{abstract}

\section{Introduction}

Patients with malignant tumors on the upper aero digestive way need a multidisciplinary treatment [1]. These tumors treatment can be done through surgery, radiation therapy (RT) and chemotherapy. All these treatments increase the rate of comorbidities that can be reversible or irreversible [2]. Oral Mucositis refers to oral mucosa erythematous and ulcerative lesions observed in patients being treated with radiotherapy (RT) for head and neck cancer [3]. Mucositis is related as severe in $30.0-40.0 \%$ of the cases [4,5]. Multinational Association for Support and care of Cancer and the International Society of Oral Oncology (MASCC/ISOO) advocated the use benzydamine as a treatment for mucositis, a topical anti-inflammatory drug, with fluconazole. This protocol requires the combination of two drugs being that benzydamine has alcohol in formulation and may cause irritation and burning, these was the most frequently reported toxicity [6-9]. The term propolis comes from greek pro-"in front of, on the entrance of" and polis-"community or city" [10-12]. The chemical composition of propolis is complex, and some factors such as plant ecology of the region where the propolis was collected and also the genetic variability of the queen bee, can influence on the chemical composition of the resin material [13-15]. Nowadays, it is known that propolis shows several biological activities such as antimicrobial, anti-inflammatory, anesthetic and cytostatic properties [16]. This product activity should prevent mucositis pathophysiology characteristics [6] and properties of propolis [17]. The aim of this prelimary study was the verify the effectiveness of Brazilian green propolis in a mucoadhesive gel, alcohol free, in preventing oral mucositis in patients that underwent RT in head and neck region compared with a benzydamine (0.15\%) alcoholic solution.

\section{Patients and methods}

This research is characterized as a preliminary study with a mean duration of 12 weeks of patients' follow-up. A gel containing propolis manipulated within the standards required by ANVISA (Brazil, 2000), ISO 9001 and GMP International. Propolis was collected and manipulated according to the technical standards of the Brazilian Pharmacopoeia (2015). For inclusion in this study the patients must have a confirmed diagnosis of malignant lesion in head and neck RT, submitted to a dose higher than 50 Gys. The selection of participants to groups was randomized and conditioned to availability of the patients attend the study during RT [18]. All patients signed informed consent prior to participation and the Ethics Committee on Human Research (COEP/UFMG) approved the study under number CAAE 04328812.1.0000.5149. A total of 70 patients were initially enrolled in the study. Twenty-six patients were included in these studies and divided in two groups: group 1 used benzydamine with fluconazole according MASCC/ISOO and group 2 used mucoadhesive gel with propolis $5 \%$. Flow diagram about the clinical trial design study is shown in Figure 1. All selected patients, were administered on the first day of RT propolis gel-every 8 hours $(6 \mathrm{~h}, 14 \mathrm{~h}, 22 \mathrm{~h})$. It was used on the first day of RT and it was indicated its administration for another two weeks after the last session of RT. For patients in the control group benzydamine, protocol

Correspondence to: SantosVR, Av. Pres. Antônio Carlos, 6627-Pampulha, Belo Horizonte-MG, 31270-901, Brazil, Tel: 553134092497; Fax: 553134092430; E-mail vegneer2003@yahoo.com.br

Key words: mucositis, oncology, radiotherapy, chemotherapy, propolis

Received: February 02, 2017; Accepted: February 15, 2017; Published: February 17,2017 


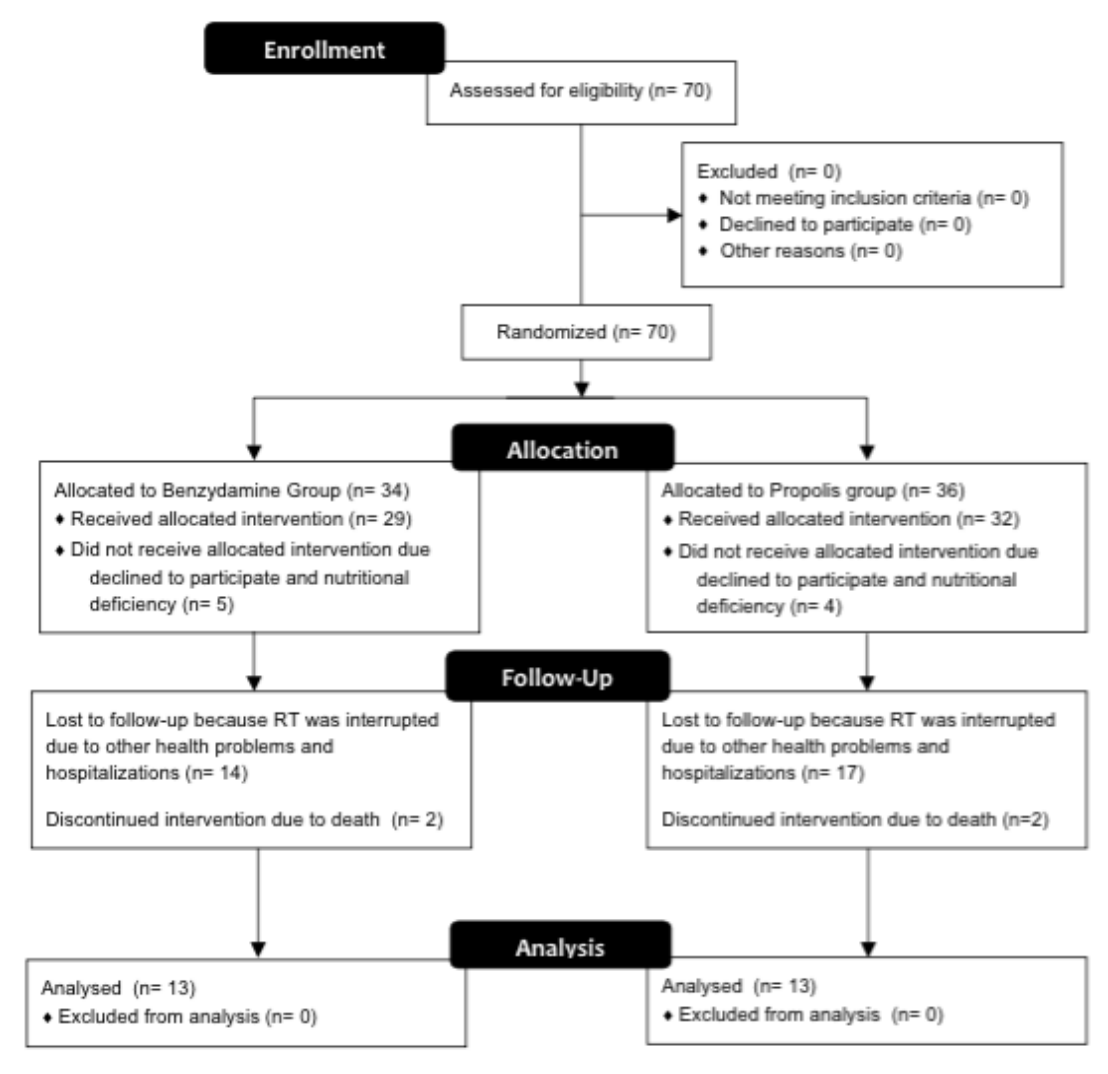

Figure 1. Clinical trials flow diagram.

according to the MASCC/ISOO, it was administered following the same dosage used for the gel containing propolis, however, fluconazole was prescribed only for patients with clinical features of infection with Candida spp. All study patients were evaluated every 7 days during the whole period of RT. The World Health Organization (WHO) scale performed the evaluation of the degree of mucositis [7]. The same examiner, using the same initial criteria, made these assessments. These tests were considered: intra-oral examination (soft tissue changes), data collection for the presence or absence of candidiasis.

\section{Statistical analysis}

The statistical analysis began by checking the homogeneity of demographic and clinical quantitative variables between the benzydamine and the propolis gel groups with the Mann-Whitney statistical test [19]. Fisher's Exact Test was used for homogeneity of qualitative variables between the groups [20]. This research is a study of completely unbalanced repeated measures. To evaluate all factors that exert influence on the grade of mucositis, two levels of mucositis, "mucositis grade $<2$ " and "mucositis grade $\geq 2$ ", were set to analyze. However, this study should, in a careful manner, model the structure of the medium, i.e., as the average percentage of the higher degree of mucositis equal to 2, behave along the RT sessions. For this, the Splines method [22] was used with a knot in the in the tenth seventh session of $\mathrm{RT}$, to set graphical views using nonparametric regression via LOWESS method [21]. These segments are called Splines and the location where the lines meet is called knot [22]. Thus, we call the adjusted models as Logistic Marginal Regression Splines, in which we evaluate the significance of the variables of interest and its interaction with the number of sessions on two occasions, before and after the session RT 17. Marginal Logistic Regression Splines was first used to check for significant differences in the average percentage of the higher degree of mucositis equal to 2, along the RT sessions between the Benzydamine and the propolis groups. To select the set of significant variables, the stepwise selection method variables were used [23]. The stepwise method is defined as a mixture of Backward and Forward methods. The Forward method in this study was carried out via analysis of deviation from univariate regressions, using a p-value of 0.25 for entering variables in the multivariate model. On all variables selected by the forward method, we applied the backward method with a significance level of 5\%. The software used in the analysis was the $\mathrm{R}$ version 3.0.1.

\section{Results}

Epidemiological data and the homogeneity of demographic and clinical quantitative variables between groups are shown in Table 1 . Treatment for other systemic changes was reported by $57.7 \%(n=15)$ of patients, the most frequent cardiovascular disorders with $73.3 \%$ $(n=11)$ of cases. The chemotherapy was performed in $6(46.2 \%)$ benzydamine group and 3 (23.1\%) propolis group. The chemotherapy did not interfere in the result as a whole, because the p-variable showed no significant variation $(0.179)$ to say that the groups were different from each other. The number of sessions of RT in primary lesion was 33.39 ( \pm 4.04$)$, ranging from 20 to 39 sessions. The total dose of RT in primary lesion was, on average, 6466.1 cGy range 5000-7200 cGy. The extent of mucositis was performed along the RT sessions on average 4.5 times ranging from 2-7 per patient ratings. In total 116 diagnoses mucositis, benzydamine in the group 62 and group 54 in the gel were propolis. The total number of diagnosis $(n=116)$ with mucositis grade 2 or higher was $30.6 \%$ in the benzydamine group and $29.6 \%$ in the propolis group according to Table 2 . To visualize the behavior along the sessions of RT, the mucositis percentage of grade 2 or higher 
Table 1. Homogeneity according to clinical and demographic variables between the study groups.

\begin{tabular}{|c|c|c|c|c|c|c|}
\hline \multicolumn{2}{|l|}{ Variables } & \multicolumn{2}{|c|}{ Benzydamine (n=13) } & \multicolumn{2}{|c|}{ Propolis $(n=13)$} & \multirow{3}{*}{$\begin{array}{r}\text { p-Value } \\
0.593\end{array}$} \\
\hline \multirow{2}{*}{ Gender } & Female & 3 & $23.10 \%$ & 1 & $7.70 \%$ & \\
\hline & Male & 10 & $76.90 \%$ & 12 & $92.30 \%$ & \\
\hline \multicolumn{2}{|l|}{ Age-Average (SD) } & 54.1 & -15 & 53.7 & -12.9 & 0.938 \\
\hline \multirow{2}{*}{ Medical Treatment } & No & 4 & $30.80 \%$ & 7 & $53.80 \%$ & \multirow{2}{*}{0.428} \\
\hline & Yes & 9 & $69.20 \%$ & 6 & $46.20 \%$ & \\
\hline \multirow{2}{*}{ Smoking } & No/Ex-Smoker & 11 & $84.60 \%$ & 10 & $76.90 \%$ & \multirow{2}{*}{1} \\
\hline & Yes & 2 & $15.40 \%$ & 3 & $23.10 \%$ & \\
\hline \multirow{2}{*}{ Alcoholic Beverages } & No & 12 & $92.30 \%$ & 9 & $69.20 \%$ & \multirow{2}{*}{0.322} \\
\hline & Yes & 1 & $7.70 \%$ & 4 & $30.80 \%$ & \\
\hline \multirow{2}{*}{ Histological Type } & $\mathrm{CCE}$ & 9 & $69.20 \%$ & 11 & $84.60 \%$ & \multirow{2}{*}{0.645} \\
\hline & Other & 4 & $30.80 \%$ & 2 & $15.40 \%$ & \\
\hline \multirow{4}{*}{ Location } & Larynx & 2 & $15.40 \%$ & 5 & $38.50 \%$ & \multirow{4}{*}{0.372} \\
\hline & Tongue & 4 & $30.80 \%$ & 1 & $7.70 \%$ & \\
\hline & Oropharynx & 3 & $23.10 \%$ & 2 & $15.40 \%$ & \\
\hline & Other sites & 4 & $30.80 \%$ & 5 & $38.50 \%$ & \\
\hline \multirow{2}{*}{ Chemotherapy } & No & 3 & $23.10 \%$ & 7 & $53.80 \%$ & \multirow{2}{*}{0.179} \\
\hline & Yes & 6 & $46.20 \%$ & 3 & $23.10 \%$ & \\
\hline \multicolumn{3}{|c|}{ Number of Primary Lesion sessions - Average (SD) } & $33.6(5.9)$ & \multicolumn{2}{|c|}{$33.2(3.2)$} & 0.289 \\
\hline \multicolumn{3}{|c|}{ Total dose of RT Primary Lesion - Mean (SD) } & $6534.5(742.1)$ & \multicolumn{2}{|c|}{$6403.3(477.1)$} & 0.476 \\
\hline
\end{tabular}

Table 2. Degree of mucositis in all evaluations by study group.

\begin{tabular}{|c|c|c|c|c|}
\hline \multirow{2}{*}{$\begin{array}{c}\text { Degree of } \\
\text { mucositis }\end{array}$} & \multicolumn{2}{|c|}{ Benzydamine } & \multicolumn{2}{|c|}{ Propolis } \\
\cline { 2 - 5 } & $\mathbf{N}$ & $\mathbf{\%}$ & $\mathbf{N}$ & $\%$ \\
\hline 0 & 30 & $48.4 \%$ & 31 & $57.4 \%$ \\
\hline 1 & 13 & $21.0 \%$ & 7 & $13.0 \%$ \\
\hline$<2$ & 43 & $69.4 \%$ & 38 & $70.4 \%$ \\
\hline 2 & 12 & $19.4 \%$ & 8 & $14.8 \%$ \\
\hline 3 & 6 & $9.7 \%$ & 8 & $14.8 \%$ \\
\hline 4 & 1 & $1.6 \%$ & 0 & $0.0 \%$ \\
\hline$\geq 2$ & 19 & $30.6 \%$ & 16 & $29.6 \%$ \\
\hline
\end{tabular}

between benzydamine hydrochloride and gel containing propolis was used the scatter diagram using nonparametric regression via LOWESS method that can be observed in Figure 2. Thus, it is observed that in both groups there was an increase of the percentage of mucositis with a grade equal to 2 or higher, to the $17^{\text {th }}$ session, and in this interval the propolis group showed a higher percentage ( $>40 \%)$. In Figure 3 we can observe that after the $17^{\text {th }}$ session of RT the propolis group showed a decrease in the percentage of mucositis with a grade equal to 2 or higher, while the benzydamine hydrochloride group tended to stabilize at $40 \%$ of mucositis with a grade equal to 2 or higher.

The follow up after RT it was performed for five weeks and in this period patients no had mucositis.

\section{Discussion}

Several authors reported that mucositis is multifactorial and changes in the physiology of the mucosa by the action of radiation have different effects acting simultaneously leading to the reported side effects. In order to avoid these changes, the scientific community has been seeking ways to minimize adverse effects. The basic therapy of mucositis should include drugs that should have antifungal, antiinflammatory, antioxidants and healing effects $[3,4,24]$. The results on mucositis in this study are compared to several studies marked by MASCC/ISOO $[7,9]$. The number of patients without or with mucositis and mucositis grade I presented in this study $( \pm 70 \%)$ agree with other results described in the literature $[3,25,26]$. The green propolis has in its

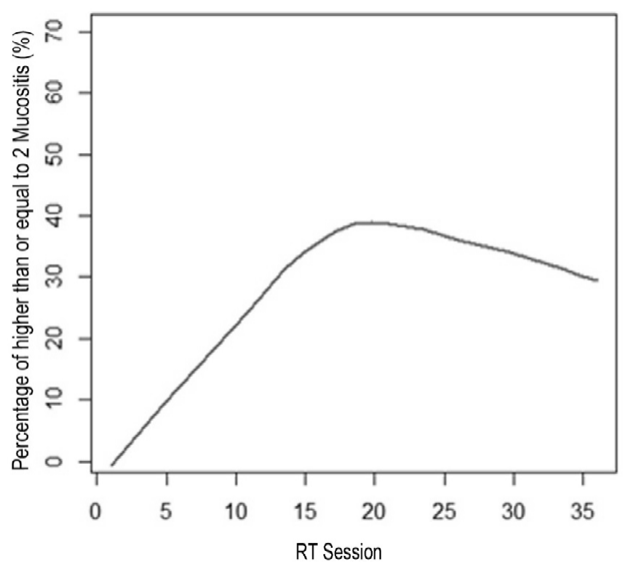

Figure 2. Smoothing method through LOWESS to the percentage of mucositis along the RT sessions for both groups.

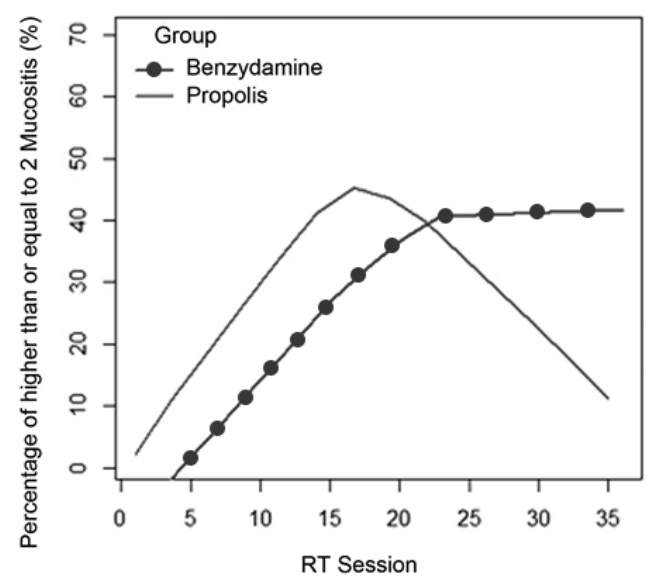

Figure 3. Smoothing method through the LOWESS method to the percentage of mucositis along the RT sessions by group. 
chemical constitution various flavonoids such as galangin and artepillin C, characterizing this compound as anti-inflammatory, antimicrobial and antioxidant [27,28]. Such features described in the literature are important for the prevention of mucositis because when the knowledge of the pathophysiology of mucositis and the knowledge of the products used in choice of treatment of mucositis [6] were associated, it became clear that the propolis gel without alcohol prevented inflammation, reduced free radicals and showed antifungal effects. All these features gathered in a single product make it more advantageous than other products such as benzydamine, which is an alcoholic solution and requires association with fluconazole. Propolis gel also has advantages over products made from salt, considering that the percentage of patients with cardiovascular disorders can't be neglected, because some products use saturated salt in their formulation [29]. Patients with diabetes should also be treated with caution because some authors recommend the use of honey [30,31]. Since some products use saturated salt in their formulation [29] and the percentage of patients with cardiovascular disorders can't be neglected, propolis gel has also advantages over those products. Patients with diabetes should also be treated with caution because some authors recommend the use of honey [30,31].

\section{Conclusion}

In this study, we observed a better behavior of the gel containing propolis regarding benzydamine after the $17^{\text {th }}$ session of RT. This has been justified by anti-inflammatory and antifungal characteristics of propolis. Since the mucositis is caused by inflammation and aggravated by the presence of fungus, it is predictable that patients with the continued use of this propolis containing product can have a better oral health. Mucositis is exacerbated by the extent and amount of applied radiation. Observing patients in more advanced stages of the malignant tumors of the head and neck treatment, we note that the presence of mucositis in lower levels is the expected effect for the patients treated with propolis gel. Since the propolis gel have good acceptance by patients, this study points to the necessity of further research in Phase III to obtain more significant results.

\section{Acknowledgment}

CAPES - Coordenacao de Aperfeicoamento de Pessoal de Nivel Superior. FAPEMIG - Foundation of aid the research of the state of Minas Gerais (17174 FAPEMIG/FO/DCPCO/Mucositis and Candidose).

\section{References}

1. Gourin CG, McAfee WJ, Neyman KM, Howington JW, Podolsky RH, et al. (2005) Effect of comorbidity on quality of life and treatment selection in patients with squamous cell carcinoma of the head and neck. Laryngoscope 115: 1371-1375. [Crossref]

2. Beech N, Robinson S, Porceddu S, Batstone M (2014) Dental management of patients irradiated for head and neck cancer. Aust Dent J 59: 20-28. [Crossref]

3. Lalla RV, Saunders DP, Peterson DE (2014) Chemotherapy or radiation-induced oral mucositis. Dent Clin North Am 58: 341-349. [Crossref]

4. Sonis ST, Elting LS, Keefe D, Peterson DE, Schubert M, et al. (2004) Perspectives on Cancer Therapy-Induced Mucosal Injury. Cancer 100: 1995-2025.

5. Eilers J, Million R (2011) Clinical update: prevention and management of oral mucositis in patients with cancer. Semin Oncol Nurs 27: e1-e16. [Crossref]

6. Sonis ST (2004) A biological approach to mucositis. J Support Oncol 2: 21-32. [Crossref]

7. Lalla RV, Sonis ST, Peterson DE (2008) Management of oral mucositis in patients who have cancer. Dent Clin North Am 52: 61-77. [Crossref]

8. Rosenthal DI, Trotti A (2009) Strategies for managing radiation-induced mucositis in head and neck cancer. Semin Radiat Oncol 19: 29-34. [Crossref]

9. Nicolatou-Galitis O, Sarri T, Boewn J, Palma MD, Kouloulias VE, et al. (2013) Systematic review of anti-inflammatory agents for the management of oral mucositis in cancer patients. Support Care Cancer 21: 3179-3189. [Crossref]

10. Castaldo S, Capasso F (2002) Propolis, an old remedy used in modern medicine. Fitoterapia 73 Suppl 1: S1-S6. [Crossref]

11. Salatino A, Teixeira EW, Negri G, Message D (2005) Origin and Chemical Variation of Brazilian Propolis. Evid Based Complement Alternat Med 2: 33-38. [Crossref]

12. Sforcin JM, Bankova V (2011) Propolis: is there a potential for the development of new drugs? J Ethnopharmacol 133: 253-260. [Crossref]

13. Burdock GA (1998) Review of the biological properties and toxicity of bee propolis (propolis). Food Chem Toxicol 36: 347-363. [Crossref]

14. Boyanova L, Kolarov R, Gergova G, Mitov I (2006) In vitro activity of Bulgarian propolis against 94 clinical isolates of anaerobic bacteria. Anaerobe 12: 173-177. [Crossref]

15. Sforcin JM (2007) Propolis and the immune system: a review. J Ethnopharmacol 113: 1-14. [Crossref]

16. Bankova V (2005) Recent trends and important developments in propolis research. Evid Based Complement Alternat Med 2: 29-32. [Crossref]

17. Wagh VD (2013) Propolis: a wonder bees product and its pharmacological potentials. Adv Pharmacol Sci 2013: 308249. [Crossref]

18. Kazemian A, Kamian S, Aghili M, Hashemi FA, Haddad P (2009) Benzydamine for prophylaxis of radiation-induced oral mucositis in head and neck cancers: a doubleblind placebo-controlled randomized clinical trial. Eur J Cancer Care 18: 174-178.

19. Hollander M, Wolfe DA (1999) Nonparametric Statistical Methods. John Wiley \& Sons, New York

20. Agresti A (2002) Categorical data analysis. Wiley, New York

21. Cleveland WS (1979) Robust Locally Weighted Regression and Smoothing Scaterplots J Am Stat Assoc 829: 36.

22. Fitzmaurice GM, Laird, NM, Ware JH (2011) Applied Longitudinal Analysis. John Wiley \& Sons, New Jersey, USA

23. Efroymson MA (1960) Multiple regression analysis. Mathematical Methods for Digital Computers.

24. Scardina GA, Pisano T, Messina P (2010) Oral mucositis. Review of literature. $N Y$ State Dent J 76: 34-38. [Crossref]

25. Ray-Chaudhuri A, Shah K, Porter RJ (2013) The oral management of patients who have received radiotherapy to the head and neck region. Br Dent $J$ 214: 387-393.

26. Campos MI, Campos CN, Aarestrup FM, Aarestrup BJV (2014) Oral Mucositis in Cancer Treatment: Natural history, Prevention and Treatment (Review). Mol Clin Oncol 2: 337-340. [Crossref]

27. Pereira EMR, Silva JLDC, Silva FF, De Luca MP, Ferreira e Ferreira E, et al. (2011) Clinical Evidence of the Efficacy of a Mouthwash Containing Propolis for the Control of Plaque and Gingivitis: A Phase II Study. Evidence-Based Complementary and Alternative Medicine.

28. Moura SAL, Ferreira MAND, Andrade SP, Reis MLC, Noviello ML, et al. (2011) Brazilian Green Propolis Inhibits Inflammatory Angiogenesis in a Murine Sponge Model. Evidence-Based Complementary and Alternative Medicine.

29. Rao NG, Trotti A, Kim J, Schell MJ, Zhao X, et al. (2014) Phase II multicenter trial of Caphosol for the reduction of mucositis in patients receiving radiation therapy for head and neck cancer. Oral Oncology 50: 765-769.

30. Motallebnejad M, Akram S, Moghadamnia A, Moulana Z, Omidi S (2008) The effect of topical application of pure honey on radiation-induced mucositis: a randomized clinical trial. J Contemp Dent Pract 9: 40-47. [Crossref]

31. Yarom N, Ariyawardana A, Hovan A, Barasch A, Jarvis V, Jensen SB, Zadik Y, Elad S, Bowen J, Lalla RV (2013) Systematic review of natural agents for the management of oral mucositis in cancer patients. Support Care Cancer 21: 3209-3221.

Copyright: (C2017 Noronha VRAS. This is an open-access article distributed under the terms of the Creative Commons Attribution License, which permits unrestricted use, distribution, and reproduction in any medium, provided the original author and source are credited. 